\title{
Investigación \\ La preservación del patrimonio audiovisual. Funciones de la filmoteca
}

José Enrique Monasterio Morales

Director de la Filmoteca de Andalucía (Córdoba)

\section{Resumen}

El cine está cimentado sobre una base industrial que ha prodigado su explotación como fenómeno de masas. Su capacidad integradora y sus múltiples naturalezas le han otorgado el carácter de Arte, Documento, Fenómeno Social y, finalmente, al abrigo de su presencia popular, el de Patrimonio Audiovisual de la Humanidad. Sin embargo, en comparación con otras artes, paradójicamente, a pesar de ser un invento relativamente reciente, su naturaleza orgánica le impide su pervivencia en el tiempo. En este contexto surge la necesidad imperiosa de conservar su legado y es aquí donde comienza la creación de las Filmotecas y de su misión.

Básicamente todas las Filmotecas recogen en los estatutos de su creación las funciones de Preservación del Patrimonio Audiovisual, Documentación, Investigación y Difusión. Sin embargo, existen distintas tipologías en función de su titularidad, especialización o marcos territoriales.
El cine como realidad física frágil que merece ser investigada, conservada, restaurada, documentada y difundida

El cine no tiene futuro. Esta frase de los hermanos Lumière no sólo pone de manifiesto su ingenua falta de fe en aquel invento que maravi lló en la mítica proyección del Salón Indio del Grand Café del Boulevard des Capucines, el 28 de diciembre de 1895, sino que, quizás, de manera cruel, se contraponga a la frase de "El cine no tendrá pasado" y que lamentablemente planea sobre su futuro. Porque desgraciadamente, si no lo remediamos, ésta es una de las realidades en la memoria de cine: el soporte cinematográfico es perecedero, resiste mal el paso del tiempo. Tenemos delante de nosotros su segura desaparición.

Lo mismo que podemos contemplar las pinturas rupestres en las Cuevas de Altamira es posible que, de no tomar las medidas adecuadas, tengamos la contradicción de que aquel fenómeno que nació siglos más tarde, y al que Ricciotto Canudo ${ }^{1}$, en 1911, definió como el Séptimo Arte, desaparezca en su historia. ¿Historia del cine? ¿De qué hablamos cuando la nombramos? ¿Un siglo de patentes y espectadores hipnotizados?

Dejando de lado las teorias metodológicas con las que nos abordan las corrientes de estudiosos para definir la historia del cine, debemos tener en cuenta que nos enfrentamos a una disciplina con una vida centenaria, y eso implica algunas consideraciones en la perspectiva patrimonial. Pues un siglo apenas es nada en el conjunto cronológico de cualquier historia, o si no ¿Qué ocurre cuando nos cuentan que tal civilización vivió durante tantos siglos en determinado espacio? Le concedemos una importancia relativa a su huella en nuestra herencia actual, remitiéndonos al estudio y conservación de todos los restos que puedan existir de ese lejano pasado. Sin embargo, nos hacemos la ilusión de que nuestra época, y con ella nuestro cine, serán más afortunados y permanentes, pues como hijos de todos los avances científicos de la era digital, explotamos con júbilo juvenil una euforia que enmascara aspectos de una vejez desprevenida en la desolación de una desaparición absoluta, un aleteo furioso de pez ahogándose en el exceso de oxígeno contaminado.

La capacidad integradora es algo inherente al cine, yendo más allá de su naturaleza artística para convertirse en la ventana con la cual podemos mirar nuevos mundos y a nosotros mismos. Esta cualidad hace que sea el arte más social y lo corrobora el ambiente que rodea al fenómeno de una proyección cinematográfica siempre marcado por la ritualidad del arreglo personal, el pago en una taquilla y el paso a una acogedora oscuridad donde ejercer de voyeur privilegiado. De hecho, suele ser uno de los primeros acercamientos al mundo artístico al que nuestros padres nos conducen de la mano desde pequeños.

Si los hermanos Lumière fueron el alma, Edison, con sus patentes y sus métodos de producción, es el que realmente materializó el naci- 
miento del cine como industria. Sobre todo cuando el cine dejó de ser ese invento que pasear en los "Congresos Cientíicos" y pasó a convertirse en objeto de atención popular. Lo que a la larga le ha deparado su supervivencia. Principalmente a partir de 1905 con la creación de los "nickelodeons": especie de espacios para el ocio cinematográfico con capacidad para centenares de espectadores. Se trata de una liturgia localizada en sus oficiantes y templos que, de manera natural, va pasando de generación en generación hasta los multicines actuales. El firmamento de sus estrellas ha sustituido o complementado al devocionario particular para convertirse en la más esplendorosa religión de nuestra época.

Pero salvando estos aspectos meramente sociológicos, también el cine parte de otros que le afectan profundamente en su valor como Patrimonio. El valor de la imagen como documento, éste puede ser determinado en razón de su contenido, como por ejemplo las imá genes en $8 \mathrm{~mm}$ del asesinato de John Kennedy en Dallas por las cuales cobraron sus herederos, en 1999, 16 millones de dólares; 0 en función del contexto histórico en el que se realizaron las pelícur las, como pudiera determinar la catalogación y definición de determinadas corrientes cinematográficas que depararon géneros o movimientos rupturistas, baste mencionar como uno de esos ejemplos al cine negro americano de "la guerra fría" y el Código Hays, o al Free Cinema Británico de finales de los cincuenta. De ahí la necesidad de crear Filmotecas para su conservación urgente.

La tipología de estos archivos es muy variada y ha dado lugar a especializaciones de diverso contenido. Desde la contemplación de museos del cine, a centros especializados en épocas, soportes (televisivos, cinematográficos), temáticos (Museo de la Guerra de Londres), ámbitos geográficos nacionales o regionales. Las diversas Federaciones Internacionales, casos de la FIAF (Federación Internacional de Archivos Fílmicos), FIAT (Federación Internacional de Archivos Televisivos) analizan y procuran métodos y clasificaciones.

La representación de la visión de los tiempos en los que está inmerso y los agentes que intervienen en esa creación justifican, per se, que el cine sea conservado, aunque esta conservación no está jus tificada como un mero almacenamiento con variables estables de temperatura y humedad y sí para que podamos volver a ver esas películas en los formatos y espacios para las que fueron creadas. Si no se proyectasen las películas no existiria el cine, sería tan sólo un material físico enlatado. Esta coherente exposición para la conservación ha sido mal interpretada con medias verdades por determi nados colectivos para justificarse, ocultar carencias y perpetuar status mal entendidos que han degenerado en rivalidades departamentales y en desconfianza entre archivos e historiadores. Afortunadamente, en la actualidad, el marco de cooperación alcanzado trata de borrar esos extremismos pues está notoriamente aceptado que, como diría Raymond Borde ${ }^{2}$, "Las dos tareas están en equilibrio". Ahora se admite abiertamente que vale la pena preservar todas las imágenes en movimiento tanto por razones sociológi- cas e históricas como artísticas y culturales, y además los archivos deben ser lugares vitales del cine y espacios de estudio. También es interesante la visión de Nick Deocampo3: "Los artistas e intelectuales deben transformar los archivos en un lugar dinámico y viviente, de intercambio de ideas donde el pasado se vuelva presente. Un archivo sólo tiene sentido si, además de ser un lugar donde se conserva, logra inspirar una vida espiritual e intelectual fecunda".

Las imágenes que los archivos del mundo almacenan contienen abundante información para la herencia cultural de las sociedades y este factor tiene que ser abordado y estudiado en su importancia real, pues determina la memoria del mundo en el que vivimos. La falta de visibilidad de esta urgencia en contraposición con otros elementos patrimoniales como la arquitectura, presente en todo momento, inciden en la falta de conciencia pública. Las distintas fases del proceso industrial (producción, distribución y exhibición) añaden paralelamente nuevos elementos y problemas en el acervo patrimonial. En cada eslabón existen materiales (contratos, fotos publicitarias, revistas, carteles, etc.) que unidos a la película adquieren un valor, pero éste no incide en sí mismo sino en aquel aspecto que sirve para aumentar el valor de la película referida. Por ejemplo, un cartel es valorado en una Filmoteca por la película a la que se refiere, pero puede tener un valor muy distinto en una galería de arte.

Los cambios tecnológicos, la yuxtaposición de soportes y la creación continua de imágenes en movimiento han convulsionado notablemente el panorama audiovisual. La experiencia no sólo se cent tra en el campo cinematográfico, sino en el de la televisión e internet, complicando el debate sobre el planteamiento y prioridades de conservación en los archivos.

¿Tenemos que conservar todo? ¿Qué prioridades establecemos? ¿Qué es el Patrimonio Audiovisual? Evidentemente parece que las Filmotecas tienen que expiar la culpa de haberse incorporado tarde a la conservación, al estar siempre desbordadas ante un patrimonio siempre creciente.

De las numerosas definiciones podría destacarse la siguiente: El patrimonio audiovisual abarca, sin estar limitado a ello, lo siguiente: a) Las grabaciones sonoras, radiofónicas, cinematográficas, de televisión, en vídeo y otras producciones que incluyen imágenes en movimiento y/o grabaciones sonoras, estén o no destinadas principalmente a la difusión pública;

b) Los objetos, materiales, obras y elementos inmateriales relacionados con los medios audiovisuales, desde los puntos de vista técnico, industrial, cultural, histórico u otro; comprenden los materiales relacionados con las industrias cinematográfica, radiotelevisiva y de grabación, como las publicaciones, los guiones, las fotografias, los carteles, los materiales publicitarios, los manuscritos y creaciones diversas entre las que se cuentan los vestuarios y los equipos técnicos.

c) Conceptos como la perpetuación de técnicas y entornos caídos en desuso asociados con la reproducción y presentación de esos medios. 


\section{Investigación \\ La preservación del patrimonio audiovisual. \\ Funciones de la filmoteca \\ José Enrique Monasterio \\ Morales}

Salvado el error de hacer competir a la preservación del patrimonio audiovisual y la promoción de la difusión de la cultura del cine, sin duda producto del tiempo de los pioneros, cuando Ernst Lindgren daba mayor importancia a la preservación y Henri Langlois insistía en la prioridad de la difusión de la cultura cinematográfica, los archi vos audiovisuales deben saber impulsar la investigación y la docur mentación como elementos fundamentales para su desarrollo. Dichas funciones forman parte de la mayoría de los decretos de creación de las principales Filmotecas y atendiendo a ellas podríamos plantear el siguiente Plan director básico a desarrollar:

\section{Preservación del Patrimonio Audiovisual \\ 1: Localización \\ 2: Recuperación \\ 3: Conservación}

\section{Documentación}

1: Líneas de información a los agentes del sector

2: Líneas de información sobre el sector audiovisual

3: Líneas de atención al sector (apoyo y soluciones a sus necesidades)

\section{Investigación}

1: Fomento para la creación de bases de datos sobre aspectos relacionados con el Patrimonio Audiovisual

2: Ayudas a proyectos de investigación sobre el patrimonio audiovisual

3: Iniciativas formativas

4: Estudios transversales de otras materias relacionadas

(Biblioteconomía, Química, etc.).

\section{Difusión}

1: Fomento de la exhibición de obras audiovisuales

2: Divulgación y uso de los materiales de archivo

3: Creación y establecimiento de líneas editoriales en materias relacionadas con la investigación y el patrimonio audiovisual

4: Divulgación de las funciones y actividades del archivo

\section{Creación del marco de cooperación}

$>$ Agentes del sector

$>$ Instituciones autonómicas, estatales e internacionales

$>$ Archivos audiovisuales y Centros de Documentación nacionales e internacionales

$>$ Agentes sociales

De los puntos aquí expuestos debemos incidir en que el valor de un archivo audiovisual, al igual que en un museo, estriba en las colecciones que este archivo pueda disponer. Esto indica que el punto de partida para la creación y justificación de un archivo audiovisual es la preservación de un Patrimonio Audiovisual. Es a partir de entonces cuando se desarrollan los llamados Servicios que son las líneas de documentación alrededor de dichos materiales y, entonces, la investigación actúa como base de ambas funciones, tanto en su vertiente de apoyo a su desarrollo o como resultado de sus necesi- dades, pues todo archivo debe promoverla para su crecimiento. Hay que destacar que aquel lugar con colecciones que no lleve implícita la preservación de los materiales no puede figurar como archivo, lo mismo que una colección de libros no puede considerarse una biblioteca. Puede parecer lo mismo, al tener los mismos materiales, pero su filosofía es la que las distingue, ya que solamente puede ser considerado archivo aquel que hace preservación de sus materiales para garantizar su consulta a los usuarios y a las generaciones futuras de manera permanente en el tiempo.

Desde este orden de prioridades, la difusión, a través de la organización de actividades y ciclos, es una de las mejores bazas para dar a conocer dichas funciones y sus distintos resultados. Este factor que incide en la visualización de los archivos, y que los dinamiza entre la sociedad, tiene, por desgracia, bien por necesidad o por deformación, el peligro de terminar convirtiéndose en la principal razón de ser de un archivo audiovisual marginando a la preservación y a los servicios e investigación (la cara de la moneda inversa al oscurantismo de la conservación por la conservación anteriormente expuesta). El buen equilibrio y la buena base de estas funciones determinarán la calidad e importancia de una Filmoteca.

Como complemento añadiría que, aunque no figure por escrito en los decretos de creación de una Filmoteca, el marco de cooperación debe ser una de sus funciones y objetivos ya que cuanto más fuerte sea este marco mejores serán sus resultados y apoyos en todos los puntos mencionados.

El marco deontológico de las Filmotecas y la tenacidad de su cumpli miento marcarán algo que es intangible pero que a la larga es su mejor cualidad: la confianza depositada en ellos. Esta confianza es dificil de ganar y fácil de perder al ser éste un mundo de altas sensi bilidades y códigos no escritos.

\section{Orígenes y alcance de la preocupación}

Se podría decir que la preocupación por la conservación del cine es inherente a su propio origen en la medida en que aparecian proble mas para almacenar el exceso de producción, aunque en el fondo no era una inquietud por la preservación para la posteridad, sino preocuparse por amortizar al máximo la inversión realizada y continuar explotando el catálogo. Las películas de nitrato de los inicios del cine son altamente inflamables lo que hacia que las leyes de la policía prohibieran a los industriales del cinematógrafo que guardasen en sus talleres más de un determinado número de películas. De ahí que algunos como, por ejemplo, la casa "Gaumont" de Francia construyese un almacén de conservación a las afueras de París con el nombre de Cinemateca Gaumont. Estas instalaciones, que aprovechaban unos fuertes de la guerra de 1870, consistian en unas bodegas construidas a ras del suelo, de sólida albañilería, abovedadas y recubiertas completamente con tierra, para en caso 

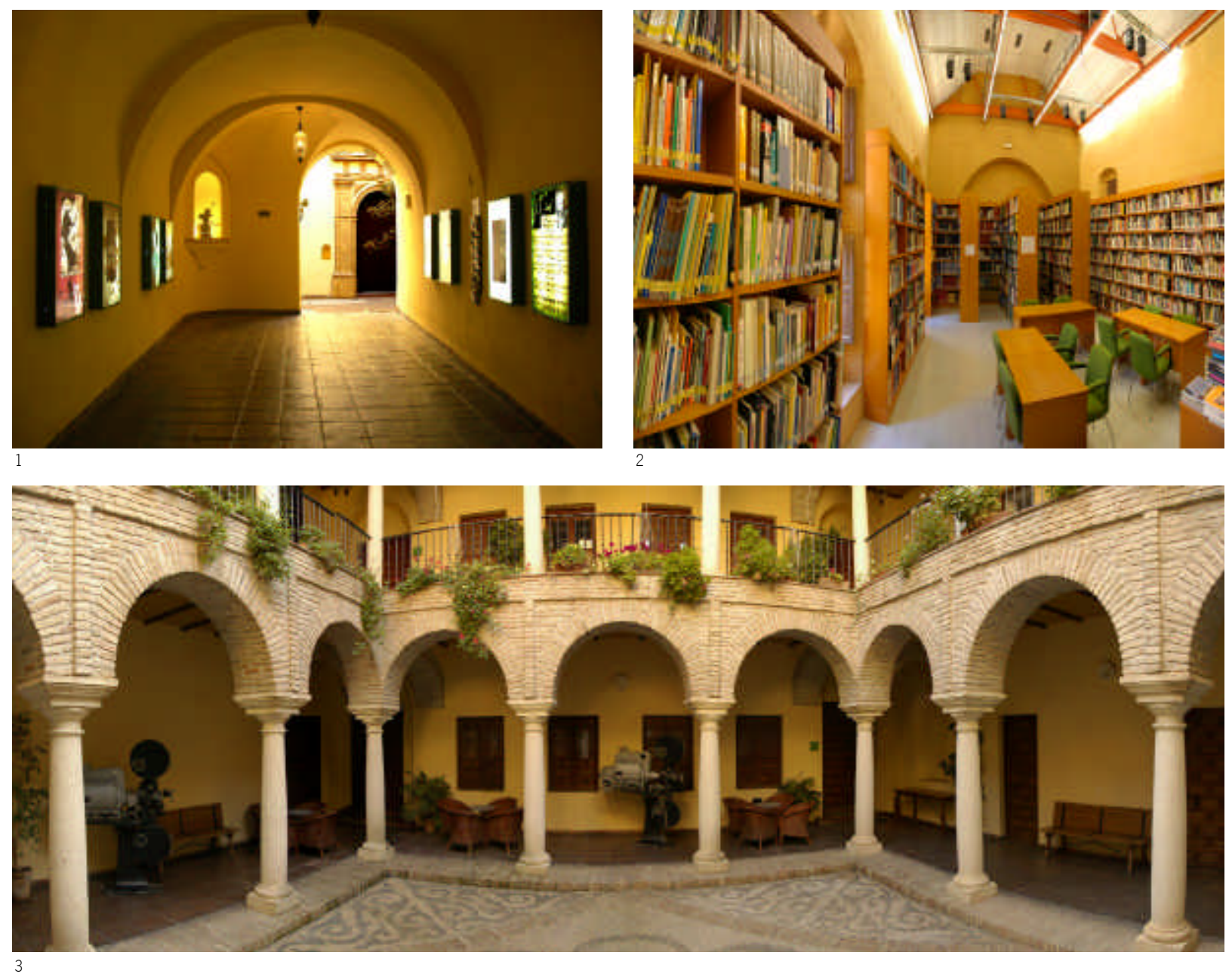

de incendio, desplomarse sobre las películas y apagar el fuego. La organización de esta cinemateca rematada con un cartel de "Prohibido fumar" correspondía al sistema de cajas instaurado en los bancos y bajo una normativa estricta, que prohibía al propietario de la película a depositar su manipulación en dichas cuevas. No obstante, también se instaló una sala de proyección para el visiona do de las películas.

Sin embargo, esta experiencia de las industrias audiovisuales tan centradas en la producción del momento, y su falta de visión como dimensión histórica de la sociedad (cosa que por otra parte sigue sin ser novedad en el momento actual) tuvo como respuesta la creación de las primeras Filmotecas en los años 30 . Las películas no tenían ningún valor y se vendían al peso. Sólo la intuición y el compromiso personal de figuras visionarias como Jean Mitry, Henri Langlois y George Franju (creadores de la Cinemateca Francesa en 1934) evita- ron que esta situación se perpetuase y de paso crearon los cimientos de la imagen romántica de las Filmotecas, pues al amparo de aquellos ciclos de cine crecieron y peregrinaron numerosos directores de prestigio y gestores culturales actuales.

El esfuerzo realizado ha sido desde entonces constante, con los naturales errores y cambios metodológicos propios de un archivo que debe enfrentarse a numerosos retos tecnológicos y legales. Al poco tiempo nació al calor de algunos contactos internacionales la Federación Internacional de Archivos Fílmicos (FIAF) en 1938. Hecho que ha facilitado el marco de cooperación y la implantación de un código deontológico muy necesario para la concienciación y dignificación de las Filmotecas.

La urgencia de esta empresa encuentra varias dificultades que podrian resumirse en: 


\section{Investigación}

La preservación del patrimonio audiovisual.

Funciones de la filmoteca

\section{José Enrique Monasterio}

Morales

\section{> La fragilidad de los soportes}

Hasta la década de los cincuenta las películas cinematográficas se realizaban básicamente sobre soportes de nitrato de celulosa plastifi cada (celuloide), un material de enorme inestabilidad química que ha provocado la pérdida de gran parte del patrimonio cinematográfico.

Desde la implantación de los soportes de seguridad (triacetato de celulosa), los archivos, en la medida de sus posibilidades técni cas y económicas, han desarrollado un enorme esfuerzo para reproducir sobre estos soportes todas las películas de épocas anteriores que han conseguido recuperar. No obstante, y pese a las enormes pérdidas sufridas por la cinematografía de los primeros sesenta años, la transferencia de las películas filmadas sobre celuloide a soportes de seguridad no ha sido concluida en ningún país del mundo.

Mientras que los viejos soportes de celuloide siguen degradándose los "soportes de seguridad" se han revelado como un material extremadamente delicado para la conservación. En Manual de Archivos Fílmicos ${ }^{4}$, Herbert Volkmann, Presidente de la Comisión de Preservación de la FIAF, advertía: Desafortunadamente, la ciencia y la práctica han demostrado que las condiciones más favorables para la preservación de los materiales en los archivos filmicos son muy criticas y permiten pocas variaciones...

Durante años, la UNESCO, la Comunidad Europea, la Federación Internacional de Archivos Filmicos (FIAF) y otros organismos internacionales y nacionales han promovido investigaciones para establecer cientificamente las condiciones mínimas necesarias para la preservación del patrimonio cinematográfico, más allá de las legitimas necesidades de la industria cinematográfica.

Esta preservación sólo puede garantizarse si los archivos son capa ces de crear y mantener almacenamientos con las condiciones adecuadas, de temperatura y humedad y, sobre todo, dotados de sis temas que garanticen su estabilidad.

\section{$>$ La falta de personal con formación especializada}

Simultáneamente, los archivos deben acometer la creación de las instalaciones y equipos técnicos necesarios para la preservación y restauración de las colecciones, y deben ser capaces de seleccionar y preparar el personal adecuado para la realización de todos estos trabajos.

Sin embargo las contrataciones y los perfiles de trabajadores no son todo lo adecuados para solucionar las carencias. No existe formación cualificada más allá de los cursos que imparten las propias Federaciones y Filmotecas. Tampoco existe la visualización de la profesión como algo específico y propio, sino más bien el complemento a otros profesionales de campos relacionados (archiveros, documen- talistas y bibliotecarios). La Administración no propone perfiles de trabajo adaptados a las necesidades de las Filmotecas. Así mismo cuando existen profesionales capacitados no se pueden contratar por cues tiones administrativas y no en función de méritos o resultados.

\section{> El esnobismo mediático}

La conservación del Patrimonio Cinematográfico sólo puede basarse en la preservación de los negativos originales de las películas, de copias master de seguridad y de copias de proyección aptas para permitir el acceso a las características originales de las obras cinematográficas.

Lamentablemente, esta política de conservación carece de alternativas. Plantearse la transferencia de las películas filmadas sobre soportes de acetato de celulosa a las nuevas generaciones de soportes de poliéster (sin duda, mucho más estables); plantearse la realización de duplicados de separación en blanco y negro desde los negativos en color, o plantearse la transferencia de las películas filmadas en sistemas fotoquímicos a las nuevas tecnologías digitales, resulta absolutamente imposible por diversos motivos.

Sin embargo, existen numerosos intereses de proyección mediática que hace incurrir a las Filmotecas en la selección de aquellos titur los que tienen consideración a nivel general y otorgan prestigio, des ligándose de otros que, quizás no tengan el mismo componente artístico, pero que son importantes para nuestra memoria. La visualización de una Filmoteca en función de los ciclos que organiza tampoco ayuda a relacionar la importancia de sus tareas fundamentales. Los programadores se convierten en estrellas y pasan a convertirse en el medio al que recurren (al igual que Disck Jockeis en el mundo musical). Al punto de considerar que una Filmoteca si no pone películas está cerrada al público.

En función de este esnobismo y al calor de intereses económicos de explotación se ha usado gratuitamente el término de restauración cuando en realidad se trata de nuevos tirajes o ediciones nuevas sobre la obra a explotar o exhibir. Parece que se trata de crear radicalmente consignas en donde tengas que estar colocado a favor o en contra (digital sí o digital no, difusión o conservación).

\section{> Las limitaciones presupuestarias para su conservación}

Las cantidades de películas existentes a nivel mundial exigen fuertes inversiones para su preservación y lo que es peor: las reproducciones obtenidas sobre soportes de poliéster tendrian que seguir siendo conservadas en almacenamientos muy controlados, y los nuevos soportes digitales carecen casi completamente de garantías de preservación.

La construcción y el mantenimiento de los archivos adecuados constituyen la única garantía posible para la conservación de Patrimonio Cinematográfico Mundial. 


\section{$>$ La falta de cultura patrimonial}

Las connotaciones negativas que tiene la palabra Patrimonio y archivo como algo relacionado con lo antiguo, telarañas y material inaccesible, ejercen una influencia perjudicial para la imagen de las Filmotecas. Es como si el cine fuera sólo propiedad de unos pocos cinéfilos y se remitiese en exclusiva a películas pesadas y de ensayo. Este sentir popular cala en los responsables poli ticos que están sometidos a presiones para cumplir en el escaso mandato con proyectos efectistas y de impacto. Por lo cual no pueden tener la visión precisa para evaluar su importancia y actuar, hipotecando a jóvenes archivos que no tienen más remedio que centrarse en la difusión para sobrevivir como proyectos.

\section{Recomendaciones internacionales}

El 27 de octubre de 1980, la UNESCO, a través de la Recomendación sobre la Salvaguardia y la Conservación de las Imágenes en Movimiento, proclamaba que la cinematografía y el audiovisual constituian una parte importante del Patrimonio Cultural, e invitaba a los Estados Miembros a "...tomar las medidas necesarias para impedir la pérdida, la eliminación injustificada o el deterioro de cualquiera de los elementos del patrimonio de imágenes en movimiento."

La Recomendación de la UNESCO culminó un largo proceso -ini ciado en los años treinta por las primeras filmotecas- de reconocimiento de la cinematografía y los registros audiovisuales como Patrimonio Cultural.

La Recomendación propuso la adopción de medidas para, por ejemplo, la adopción de sistemas de depósito legal para las imágenes en movimiento de producción nacional y de acuerdos voluntarios de depósito de producciones extranjeras, y la creación y financiación adecuada de archivos de cine y televisión.

Con anterioridad a la citada Recomendación y para estudiar y preparar las medidas a adoptar, la UNESCO había convocado una serie de reuniones, entre las que destacó la Reunión internacional de expertos sobre los requisitos especiales concernientes a la Preservación de Filmes y otros Medios Audiovisuales, celebrada en Buenos Aires en octubre de 1978.

En dicha reunión se resaltó (punto 15) que "Cada año que pasa se produce un aumento significativo de la utilización de docu mentos de imágenes filmadas en todo el mundo. [...] Al patrimonio cultural constituido a lo largo de los siglos por los medios tradicionales que son los libros y los documentos, los cuadros y otras formas de arte, viene a sumarse en el siglo XX el patrimonio cultural y científico de la imagen filmada. [...] Hay que insistir en el hecho de que el material de las imágenes filmadas se ha
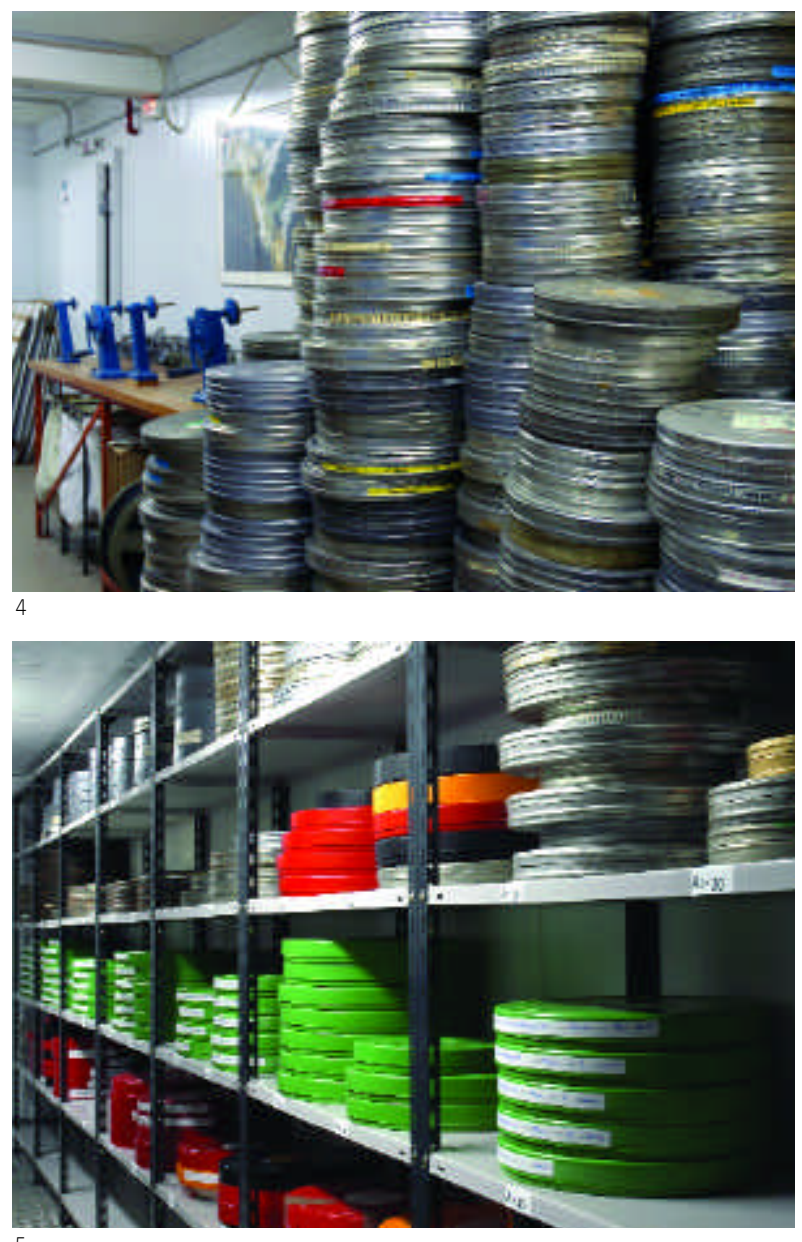

convertido ya en un rasgo fundamental de la existencia del hombre en todo el mundo, y que es probable que dichas imágenes constituyan en adelante un elemento más dominante todavía de nuestra vida cotidiana."

Por su parte, el Consejo de Europa emitió en 1979 una Recomendación sobre el Cine y el Estado, invitando a los Estados Miembros del Consejo de Europa a "organizar el almacenamiento, la conservación y la restauración de películas".

En la Recomendación sobre la Conservación del Patrimonio Cinematográfico Europeo, el Consejo de Europa, por Resolución del Consejo de 26 de junio de 2000 relativa a la conservación y promoción del patrimonio cinematográfico europeo incluye explícitamente las películas en el patrimonio cultural y social y, refiriéndose a la destrucción voluntaria y a las pérdidas involuntarias, subraya "el cometido esencial que cumplen los archivos de películas." 


\section{Investigación}

La preservación del patrimonio audiovisual.

Funciones de la filmoteca

\section{José Enrique Monasterio} Morales
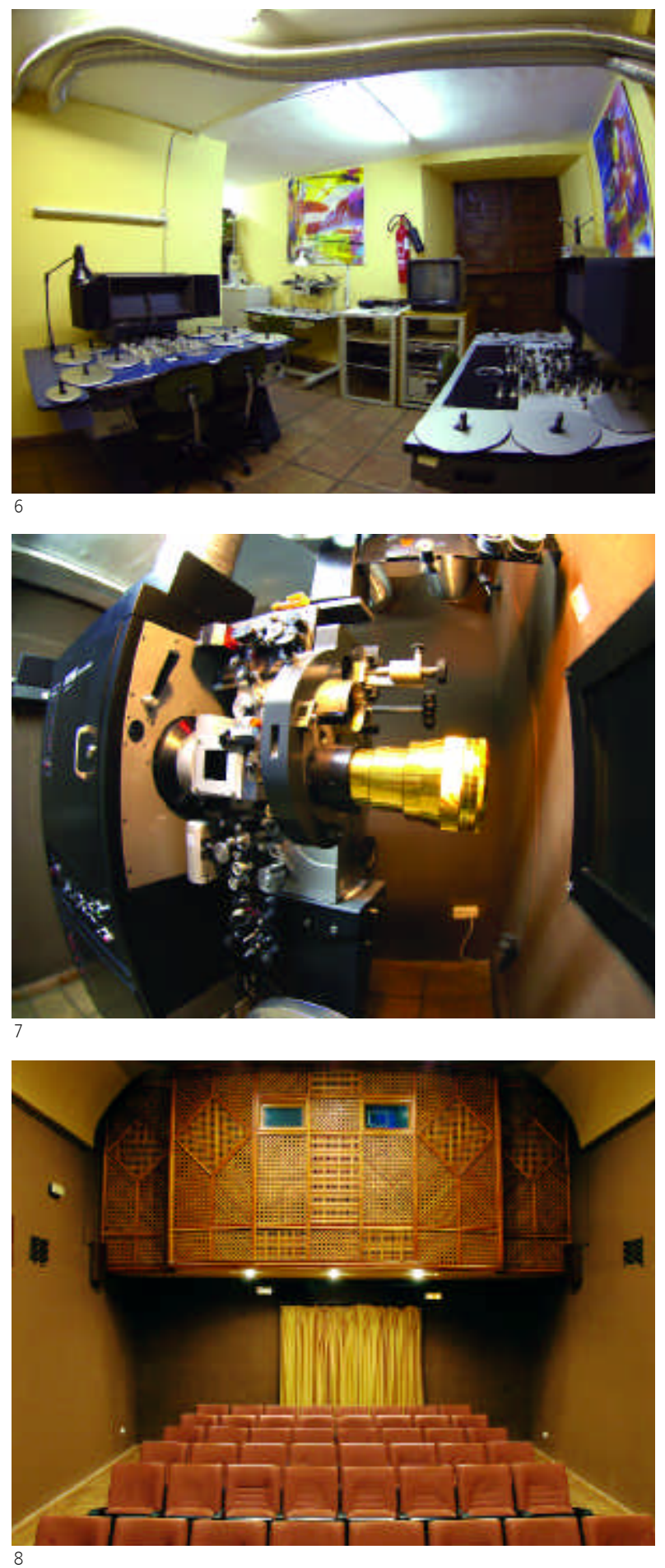

6. Sala de edición

7. Proyector

8. Sala de proyección

\section{Legislación nacional y autonómica}

En España el tema de la preservación del Patrimonio Audiovisual tuvo una entrada más tardia que el resto de los principales pioneros y llegó de la mano de la Filmoteca Nacional, actualmente llamada Filmoteca Española. Este archivo nació el 22 de marzo de 1953 en un marco de decisión estatal. Lógicamente su proceso fue evolucionando desde su entrada en la FIAF en 1956, el Real Decreto 7/1997 del 10 de enero por el cual quedan reconocidas sus funciones y los proyectos de creación de la futura sede del Centro de Conservación y restauración de la Filmoteca Española. El alcance de su presencia la consolida como referente a nivel nacional e internacional pues su marco de relaciones genera diversos fondos y actividades.

Al abrigo de la creación de los Gobiernos Autonómicos se fueron creando de forma paulatina diversas Filmotecas. Por orden de aparición tendriamos: la Filmoteca Vasca/Euskadiko Filmotegia (1978), la Filmoteca de Zaragoza (1981), la Filmoteca de Cataluña (1982), la Filmoteca Canaria (1984), la Filmoteca de Murcia (1984), la Filmoteca Valenciana (1985), la Filmoteca de Andalucía (1989), el (CGAl) Centro Galego de Artes da Imaxe (1991), Filmoteca de Castilla y León (1991), la Filmoteca Asturiana (1996), la Filmoteca de Cantabria (2001) y finalmente la Filmoteca de Extremadura (2003). La naturaleza de éstas, aunque coincide en la Preservación del Patrimonio Audiovisual, difiere en detalles de orden jurídico, pues algunas, como por ejemplo la Filmoteca de Zaragoza, no son de ámbito regional sino provincial; otras, como La Filmoteca Vasca, tuvieron su origen en una Asociación privada. El marco de actuación se circunscribe a un ámbito más reducido territorialmente. Gracias a su trabajo se puede ofrecer una imagen más completa y profunda de nuestro rico y necesario Patrimonio Audiovisual.

\section{Notas}

${ }^{1}$ CANUDO, RICCIOTO (1911) Manifiesto de las Siete Artes ["Manifesto das 7 Artes"', Paris/Fr., 1911 / CANUDO, Riccioto]

${ }^{2}$ BORDE, RAYMOND (1991) Los archivos cinematográficos Valencia : Filmoteca de la Generalitat, D.L. 1991 [traducción de Ana Montero Bosch]

${ }^{3}$ NICK DEOCAMPO Building an intellectual climate. Journal of film preservation, núm. 68. Dic. 2004

${ }^{4}$ BOWSER, ELLEEN; KUIPER, JOHN (ed). Manuel des archives du film. Bruxelles: FIAF, 1980 